\title{
$\beta$-Naphthoflavone and Ethanol Reverse Mitochondrial Dysfunction in A Parkinsonian Model of Neurodegeneration
}

\author{
Jesus Fernandez-Abascal ${ }^{1, *, \dagger}$, Elda Chiaino ${ }^{1}$, Maria Frosini ${ }^{1}{ }^{1}$, Gavin P. Davey ${ }^{2}$ and \\ Massimo Valoti ${ }^{1}$ (D) \\ 1 Dipartimento di Scienze della Vita, Università di Siena, 53100 Siena, Italy; maria.frosini@unisi.it (M.F.); \\ massimo.valoti@unisi.it (M.V.); chiaino@student.unisi.it (E.C.) \\ 2 Department of Neurodegeneration and Systems Biology, School of Biochemistry and Immunology, Trinity \\ College Dublin, D02 PN40 Dublin, Ireland; gdavey@tcd.ie \\ * Correspondence: jxf952@med.miami.edu \\ + Present address: Department of Physiology and Biophysics, University of Miami, Miller School of Medicine, \\ 1600 NW 10th Ave, Miami, FL 33136, USA.
}

Received: 23 April 2020; Accepted: 30 May 2020; Published: 31 May 2020

check for updates

\begin{abstract}
The 1-methyl-4-phenylpyridinium $\left(\mathrm{MPP}^{+}\right)$is a parkinsonian-inducing toxin that promotes neurodegeneration of dopaminergic cells by directly targeting complex I of mitochondria. Recently, it was reported that some Cytochrome P450 (CYP) isoforms, such as CYP 2D6 or 2E1, may be involved in the development of this neurodegenerative disease. In order to study a possible role for CYP induction in neurorepair, we designed an in vitro model where undifferentiated neuroblastoma SH-SY5Y cells were treated with the CYP inducers $\beta$-naphthoflavone $(\beta N F)$ and ethanol $(\mathrm{EtOH})$ before and during exposure to the parkinsonian neurotoxin, $\mathrm{MPP}^{+}$. The toxic effect of $\mathrm{MPP}^{+}$in cell viability was rescued with both $\beta \mathrm{NF}$ and $\mathrm{EtOH}$ treatments. We also report that this was due to a decrease in reactive oxygen species (ROS) production, restoration of mitochondrial fusion kinetics, and mitochondrial membrane potential. These treatments also protected complex I activity against the inhibitory effects caused by $\mathrm{MPP}^{+}$, suggesting a possible neuroprotective role for CYP inducers. These results bring new insights into the possible role of CYP isoenzymes in xenobiotic clearance and central nervous system homeostasis.
\end{abstract}

Keywords: Cytochrome P-450 system; CYP induction; CYP 2D6; CYP 2E1; mitochondrial kinetics; $\mathrm{MPP}^{+}$toxicity; neurodegeneration; neuroprotection

\section{Introduction}

Degeneration of dopaminergic neurons in the substantia nigra is a main feature of Parkinson's disease (PD). Genetic and environmental factors are known to give rise to differential proteostatic states in the brain. Additionally, cell specific energy metabolism defects and reactive oxygen species (ROS) production can enhance neurodegeneration rates [1]. ROS can also be generated by exposure to environmental xenobiotics or drug metabolism. In addition, genetic predisposition contributes to selective neurodegeneration of these cells [2-5]. High oxidative stress and disruptors of mitochondrial membrane potential $\left(\psi_{\mathrm{m}}\right)$ lead to a change in morphology and alteration in mitochondrial fusion-fission dynamics [6]. These events disrupt the overall mitochondrial homeostasis, promoting apoptosis, the release of pro-apoptotic factors, and contributing to neurodegeneration in PD and other diseases [7]. In this context, xenobiotics have emerged as one important source of oxidative stress that may lead to mitochondrial dysfunction in the brain $[8,9]$. 
A mechanism by which the cells clear xenobiotics is by the Cytochrome P-450 system (CYP), which metabolize a wide variety of molecules [10]. In the brain, CYP represents a $0.5-2 \%$ of the total amount of CYP found in the liver, but it still plays an important role in the metabolism of drugs and some endogenous compounds in the central nervous system (CNS) [11]. This superfamily has several isoforms with specific expression patterns depending on the brain area and the cell type $[12,13]$. In particular, the isoform CYP 2D6 has been related with the development of PD due to its ability to metabolize several xenobiotics in dopaminergic cells and other areas [14]. Moreover, in dopaminergic cells, the induction of CYP 2E1 by nicotine or coffee has been related with less susceptibility to PD $[15,16]$. However, the contributions of CYPs isoforms to neurodegeneration and neuroprotection toward xenobiotic insult are still poorly understood.

Induction of CYP isoforms have been generally used for the study of drug metabolism and neuroprotection in vivo and in vitro [11]. Ethanol (EtOH) and $\beta$-naphthoflavone ( $\beta N F)$ are two well-known inducers of CYP isoforms [17-19]. We previously reported that both compounds promote the induction of CYP 2D6 and 2E1, and that CYP 2D6 can be localized in mitochondria in SH-SY5Y cells [20]. The objective of the present study is to elucidate whether treatments with both inducers protect mitochondria towards the neurotoxic effect of $\mathrm{MPP}^{+}$. Our results suggest that, in parallel with induction of CYP isoforms 2D6 and 2E1, the two compounds reverse the mitochondrial impairment promoted by $\mathrm{MPP}^{+}$.

\section{Results}

\section{1. $\beta N F$ and EtOH Treatment Reduce the Loss of Cell Viability by MPP}

To study whether the induction of CYPs by $\beta \mathrm{NF}$ and $\mathrm{EtOH}$ can protect towards $\mathrm{MPP}^{+}$-induced toxicity, two different concentrations of the toxin were used in presence or absence of the two inducers (Table 1). Under this treatment protocol, we assessed cell viability based on the MTT-to-formazan metabolic activity [21]. Low $(0.6 \mathrm{mM})$ and high $(1.5 \mathrm{mM})$ concentrations of $\mathrm{MPP}^{+}$promoted a decrease in cell viability of $24 \%$ and $42 \%$, respectively (Figure 1 ). When cells were treated with $\beta$ NF prior and during exposure to $\mathrm{MPP}^{+}$itself (both concentrations), a significant recovery of $\sim 17 \%$ in cell viability was observed. EtOH showed similar results, as $\sim 15 \%$ recovery was in fact found at both $\mathrm{MPP}^{+}$ concentrations. These results suggest that $\beta \mathrm{NF}$ and $\mathrm{EtOH}$ may contribute to a better cellular protection against $\mathrm{MPP}^{+}$, possibly via CYP induction.

Table 1. Experimental protocol for drug treatments. The day after plating the cells, they were treated for $24 \mathrm{~h}$ with fresh medium containing Cytochrome P450 (CYP) inducers (see column 0-24). Afterward, the medium was replaced with fresh medium containing CYP inducers, the neurotoxin 1-methyl-4-phenylpyridinium (MPP ${ }^{+)}$or a combination of both (see column 24-48).

\begin{tabular}{ccc}
\hline Sample/Group Name & $\mathbf{0 - 2 4} \mathbf{h}$ & $\mathbf{2 4 - 4 8 ~ h}$ \\
\hline Control & Medium & Medium \\
$\beta N F$ & $\beta N F(4 \mu \mathrm{M})$ & $\beta \mathrm{NF}(4 \mu \mathrm{M})$ \\
EtOH & EtOH $(100 \mathrm{mM})$ & $\mathrm{EtOH}(100 \mathrm{mM})$ \\
$\mathrm{MPP}^{+}(0.6 \mathrm{mM})$ & Medium & $\mathrm{MPP}^{+}(0.6 \mathrm{mM})$ \\
$\mathrm{MPP}^{+}(1.5 \mathrm{mM})$ & Medium & $\mathrm{MPP}^{+}(1.5 \mathrm{mM})$ \\
$\beta \mathrm{NF}+\mathrm{MPP}^{+}(0.6 \mathrm{mM})$ & $\beta \mathrm{NF}(4 \mu \mathrm{M})$ & $\beta \mathrm{NF}(4 \mu \mathrm{M})+\mathrm{MPP}^{+}(0.6 \mathrm{mM})$ \\
$\beta \mathrm{NF}+\mathrm{MPP}^{+}(1.5 \mathrm{mM})$ & $\beta \mathrm{NF}(4 \mu \mathrm{M})$ & $\beta \mathrm{NF}(4 \mu \mathrm{M})+\mathrm{MPP}^{+}(1.5 \mathrm{mM})$ \\
$\mathrm{EtOH}+\mathrm{MPP}^{+}(0.6 \mathrm{mM})$ & $\mathrm{EtOH}(100 \mathrm{mM})$ & $\mathrm{EtOH}(100 \mathrm{mM})+\mathrm{MPP}^{+}(0.6 \mathrm{mM})$ \\
$\mathrm{EtOH}+\mathrm{MPP}^{+}(1.5 \mathrm{mM})$ & $\mathrm{EtOH}(100 \mathrm{mM})$ & $\mathrm{EtOH}(100 \mathrm{mM})+\mathrm{MPP}^{+}(1.5 \mathrm{mM})$ \\
\hline
\end{tabular}




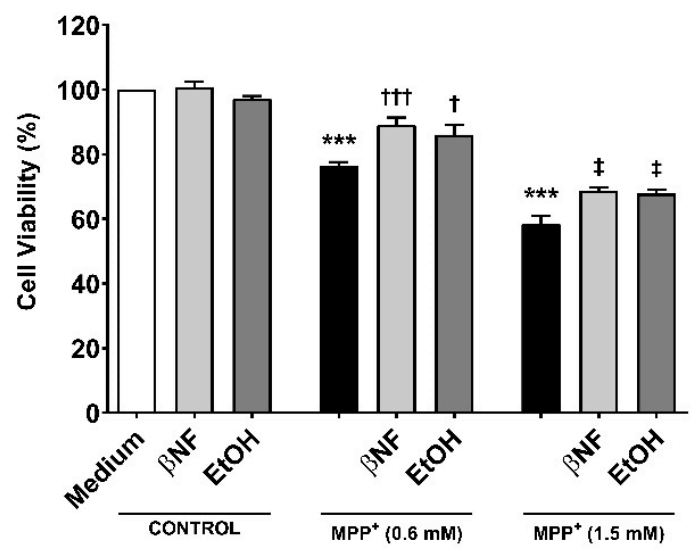

Figure 1. $\mathrm{MPP}^{+}$toxicity is reduced by $\beta$-naphthoflavone $(\beta \mathrm{NF})$ and ethanol $(\mathrm{EtOH})$ treatment. SH-SY5Y cells treated with $\mathrm{MPP}^{+}(0.6 \mathrm{mM}$ and $1.5 \mathrm{mM})$ caused a decrease in cell viability. This was calculated measuring the absorbance of formazan generated by metabolism of MTT (see methods). However, the treatment with CYPs inducers partially reversed it for both $\mathrm{MPP}^{+}$concentrations (see Table 1 for treatment details). Columns represent mean \pm SEM of independent cell culture preparations $(n \geq 3$; usually $\sim 8$, each one containing at least three biological replicates. Data are represented as percentage of control samples, whose absorbance was taken as $100 \%$ viability. ${ }^{* * *} p<0.001$ vs. $\beta \mathrm{NF}$ or EtOH; ${ }^{+++} p<0.001,{ }^{\dagger} p<0.05$ vs. $\mathrm{MPP}^{+} 0.6 \mathrm{mM} ;{ }^{\ddagger} p<0.05$ vs. $\mathrm{MPP}^{+} 1.5 \mathrm{mM}$, two-way ANOVA followed by Tukey post-test.

The protective effect of CYP induction obtained in the MTT experiments was further investigated by analyzing the formation of apoptotic/necrotic cells with Annexin V/ propidium iodide (AV/PI) staining. The early apoptotic cell population increased in an $\mathrm{MPP}^{+}$-related concentration manner $(+6 \%$ $\mathrm{MPP}^{+} 0.6 \mathrm{mM} ;+18 \% \mathrm{MPP}^{+} 1.5 \mathrm{mM}$ ) (Figure 2a). The treatments with $\beta \mathrm{NF}$ and EtOH significantly reverted the toxic effect of both concentrations of $\mathrm{MPP}^{+}$. $\beta \mathrm{NF}$ restored this population to values similar to control samples $(1.5 \%)$ in $\beta \mathrm{NF}+\mathrm{MPP}^{+}(0.6 \mathrm{mM})$ treatments, while it reduced the early apoptotic population to $9 \%$ in $\beta \mathrm{NF}+\mathrm{MPP}^{+}(1.5 \mathrm{mM})$ treatments. On the other hand, $\mathrm{EtOH}$ showed similar effectiveness, as it reduced $\mathrm{AV}+\mathrm{PI}-$ cells to control values $(1.4 \%)$ in $\mathrm{EtOH}+\mathrm{MPP}^{+}(0.6 \mathrm{mM})$, while in treatments with $\mathrm{EtOH}+\mathrm{MPP}^{+}(1.5 \mathrm{mM})$, it significantly decreased it to $7 \%$. The same protective effect was observed in late apoptotic cells with $\mathrm{MPP}^{+}(1.5 \mathrm{mM})$ treatments, as only this concentration increased the $\mathrm{AV}+\mathrm{PI}+$ cells by $14 \%$ (Figure $2 \mathrm{~b}$ ). In this case, the treatment with $\beta \mathrm{NF}$ and $\mathrm{EtOH}$ significantly reduced it to $4.8 \%$ and $5.7 \%$, respectively. Finally, the necrotic cells reached the value of $7 \%$ upon the highest $\mathrm{MPP}^{+}$concentration used, while both CYP inducers significantly reduced them to values comparable to controls (Figure 2c).

The effects of $\mathrm{MPP}^{+}$on the cell cycle were also investigated. The neurotoxin induced a concentration-dependent rise in sub-G0/G1 hypodiploid cells, typical of apoptotic-mediated cell death. In particular, the subG0/G1 group was significantly increased at both low and high $\mathrm{MPP}^{+}$ concentrations ( $6 \%$ and $10 \%$, respectively) when compared to either $\beta \mathrm{NF}$ or EtOH groups (Figure $2 \mathrm{~d}$ ). The treatment with the two inducers reverted this effect only in high concentration of $\mathrm{MPP}^{+}$, although a similar trend could be observed for low concentrations: $\beta \mathrm{NF}+\mathrm{MPP}^{+}(0.6 \mathrm{mM}), 4.6 \% ; \beta \mathrm{NF}+\mathrm{MPP}^{+}$ $(1.5 \mathrm{mM}), 6 \% ; \mathrm{EtOH}+\mathrm{MPP}^{+}(0.6 \mathrm{mM}), 4 \% ; \mathrm{EtOH}+\mathrm{MPP}^{+}(1.5 \mathrm{mM}), 6.6 \%$. These data suggest that $\beta \mathrm{NF}$ and $\mathrm{EtOH}$ decrease the apoptotic-mediated cell death caused by $\mathrm{MPP}^{+}$. 
a

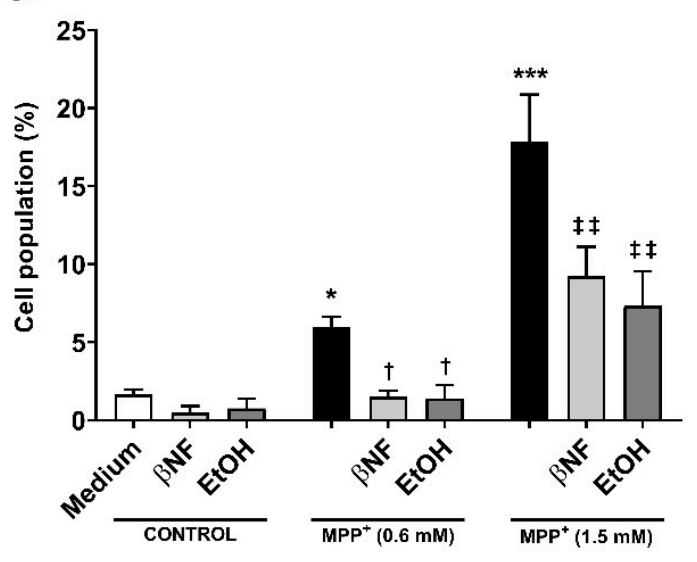

C

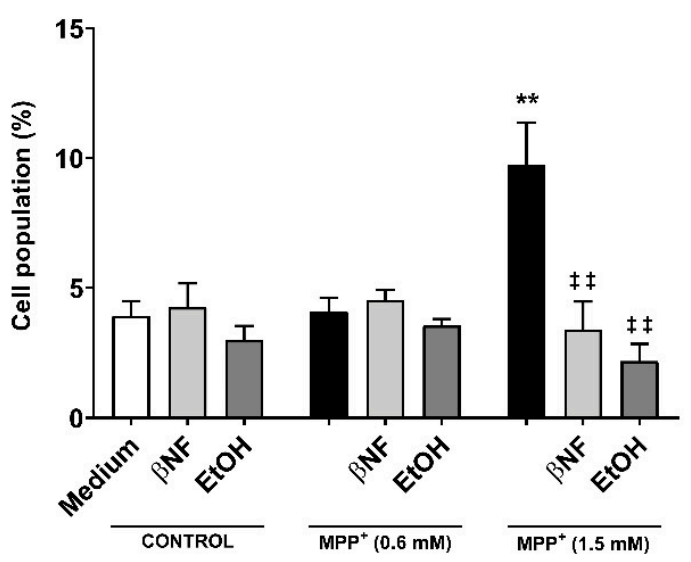

b Late Apoptotic

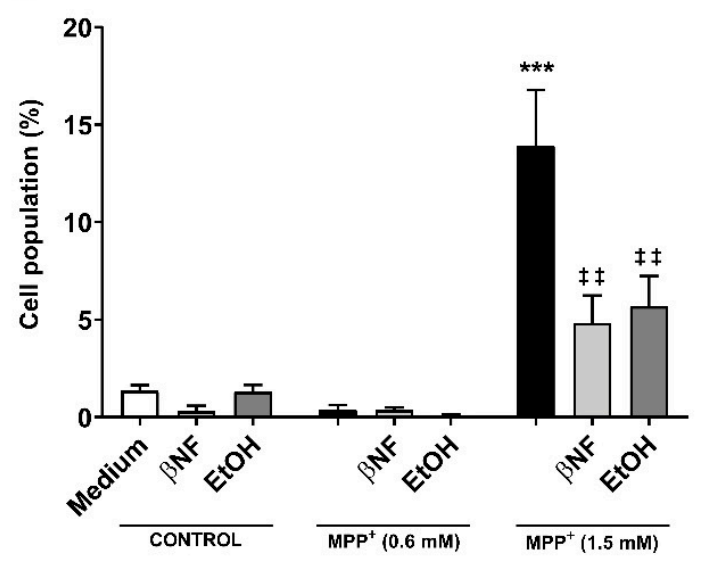

d

Sub G0/G1

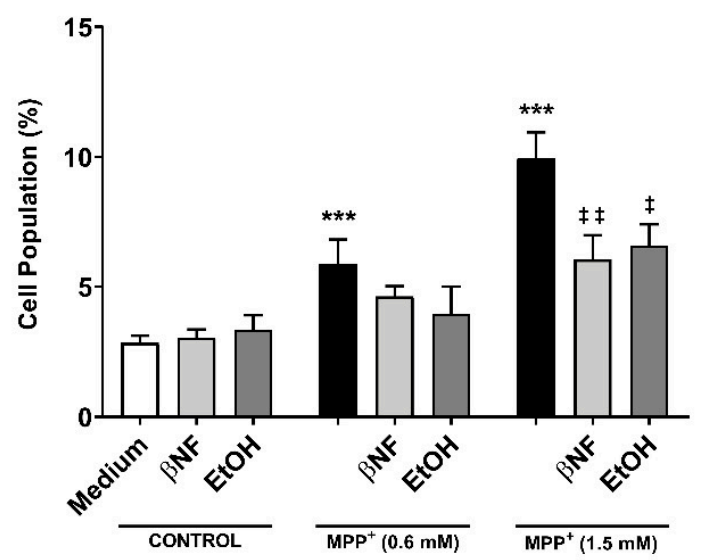

Figure 2. $\beta \mathrm{NF}$ and $\mathrm{EtOH}$ treatments reduced $\mathrm{MPP}^{+}$-mediated apoptosis. $(\mathbf{a}-\mathbf{c})$ Cell viability assay with Annexin V/PI double staining. Both $\mathrm{MPP}^{+}$treatments $(0.6 \mathrm{mM}$ and $1.5 \mathrm{mM})$ were able to increase the early apoptotic population $(\mathbf{a})$, while only $\mathrm{MPP}^{+}(1.5 \mathrm{mM})$ increased the late apoptotic $(\mathbf{b})$ and necrotic populations (c). The treatments with inducers (see Table 1) were able to rescue the apoptosis promoted by $\mathrm{MPP}^{+}$. d: $\mathrm{MPP}^{+}$promotes an increase in the percentage of hypodiploid (sub G0/G1) cells, which was reported by the increase of PI-stained DNA content. The treatment with inducers (see Table 1) partially rescued the toxic effect of $\mathrm{MPP}^{+}$. Data are reported as mean $\pm \mathrm{SEM}$ of at independent cell culture preparations $(n \geq 3$; usually $\sim 10) .{ }^{* * *} p<0.001,{ }^{* *} p<0.01,{ }^{*} p<0.05$ vs. Medium; ${ }^{\dagger} p<0.05$ vs.

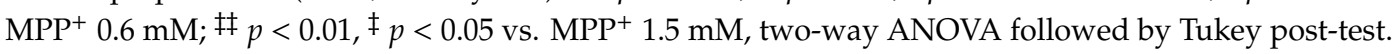

\subsection{MPP $P^{+}$-Related ROS Production is Decreased with CYP Inducers}

The treatments with $\mathrm{EtOH}$ and $\beta \mathrm{NF}$ showed that, during the exposure time to $\mathrm{MPP}^{+}$, the cells no longer underwent late apoptosis or necrosis, and only toxic effects could be observed in early apoptotic populations. This suggested that the toxicity generated by $\mathrm{MPP}^{+}$was reduced by EtOH and $\beta \mathrm{NF}$, thus the production of the initial triggers of apoptosis might also have been decreased. To pursue this idea, we measured ROS formation and found that $\mathrm{MPP}^{+}(0.6 \mathrm{mM}$ and $1.5 \mathrm{mM})$ increased DCFA fluorescence by $54 \%$ and $141 \%$, respectively (Figure 3). Interestingly, when cells were treated with the inducers, the ROS production was significantly lower in EtOH $+\mathrm{MPP}^{+}(0.6 \mathrm{mM}$ and $1.5 \mathrm{mM}: 9 \%$ and $16 \%$ increase compared to control samples, respectively; or $-83 \%$ and $-87 \%$ compared to $\mathrm{MPP}^{+}$ 
samples, respectively). In $\beta \mathrm{NF}+\mathrm{MPP}^{+}(0.6 \mathrm{mM})$, a decrease in ROS production was also observed, although not significant (15\% increase compared to control samples; or $-72 \%$ compared to $\mathrm{MPP}^{+}$ sample), while in $\beta \mathrm{NF}+\mathrm{MPP}^{+}(1.5 \mathrm{mM})$, the ROS production was significantly lower ( $6 \%$ compared to control samples; or $-104 \%$ compared to $\mathrm{MPP}^{+}$sample). These results suggest that treatment with both inducers prevents cells from undergoing apoptosis, probably by reducing ROS formation caused by the exposure to a mitochondrial-targeted toxin.

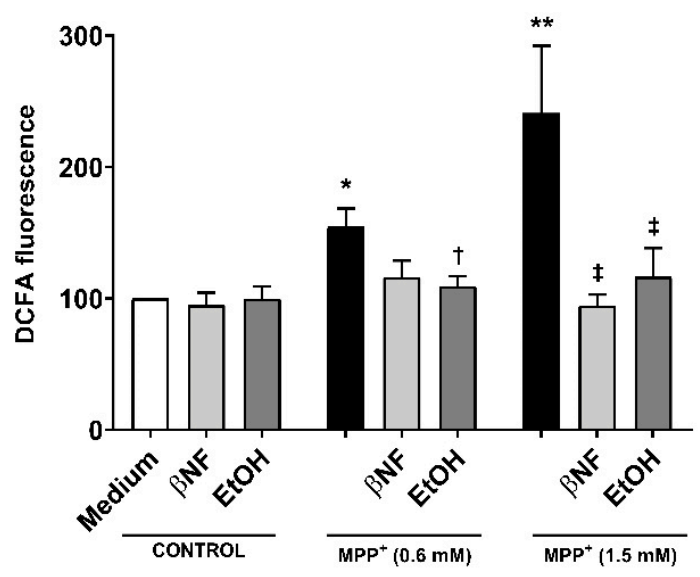

Figure 3. Reactive oxygen species (ROS) production by $\mathrm{MPP}^{+}$was decreased in cells treated with CYP inducers. $\mathrm{MPP}^{+}$treatments increased the production of ROS in SH-SY5Y cells at both concentrations. When cells were treated with $\beta \mathrm{NF}$ or EtOH prior and during exposure to $\mathrm{MPP}^{+}$(see Table 1 for treatment details), ROS production was decreased. Columns represent the percentage related to control (medium) samples of DCFA fluorescence, and data are presented as mean \pm SEM of independent cell culture preparations $(n \geq 5)$. ${ }^{* *} p<0.01,{ }^{*} p<0.05$ vs. $\beta \mathrm{NF}$ or EtOH; ${ }^{\dagger} p<0.05 \mathrm{vs} . \mathrm{MPP}^{+} 0.6 \mathrm{mM}$; $\ddagger p<0.05$ vs. $\mathrm{MPP}^{+} 1.5 \mathrm{mM}$, two-way ANOVA followed by Tukey post-test.

\subsection{Mitochondrial Fusion Kinetics Is Restored Under $\beta N F$ and EtOH Treatment}

The mitochondria is the major target for $\mathrm{MPP}^{+}$, and its fusion kinetics represent important data to evaluate the integrity of the cells, since it can work as an indicator of the first stage of apoptosis. To further investigate the apoptotic-inducing effects of $\mathrm{MPP}^{+}$, the mitochondrial fusion dynamics were studied with $\mathrm{MPP}^{+}(0.6 \mathrm{mM})$ treatments only in order to discard false positive results from late apoptotic or necrotic cells that would be found with $\mathrm{MPP}^{+}(1.5 \mathrm{mM})$ treatments.

For the $\mathrm{MPP}^{+}(0.6 \mathrm{mM})$ control, the fluorescent intensity of the photo-activated area decreased from $100 \%$ to $58 \%$ in 25 minutes (Figure 4 and Supplementary Figure S1), while control condition showed higher fusion dynamics $(29 \%$ intensity at $25 \mathrm{~min})$. In both $\beta \mathrm{NF}+\mathrm{MPP}^{+}(0.6 \mathrm{mM})$ and $\mathrm{EtOH}+$ $\mathrm{MPP}^{+}(0.6 \mathrm{mM})$ treatments, the intensity of the photo-activated area showed a higher rate of decrease than in $\mathrm{MPP}^{+}(0.6 \mathrm{mM})$ control. Indeed, the results showed that 25 minutes post-activation, the plasmid containing the photo-activatable green fluorescent protein (PA-GFP) intensity decreased from $100 \%$ to $30 \%$ for $\beta \mathrm{NF}+\mathrm{MPP}^{+}(0.6 \mathrm{mM})$ and to $28 \%$ for $\mathrm{EtOH} \mathrm{MPP}^{+}(0.6 \mathrm{mM})$ treatment, values similar to control samples. Moreover, at minute 45 post-activation, this intensity decreased until $19 \%$ for $\beta \mathrm{NF}+\mathrm{MPP}^{+}(0.6 \mathrm{mM})$ and to $15 \%$ for $\mathrm{EtOH}+\mathrm{MPP}^{+}(0.6 \mathrm{mM})$ treatment, while $\mathrm{MPP}^{+}(0.6 \mathrm{mM})$ only reached a $46 \%$ intensity. Under our experimental conditions, both treatments were able to avoid the mitochondrial instability promoted by $\mathrm{MPP}^{+}$, resulting in normal fusion dynamics. 

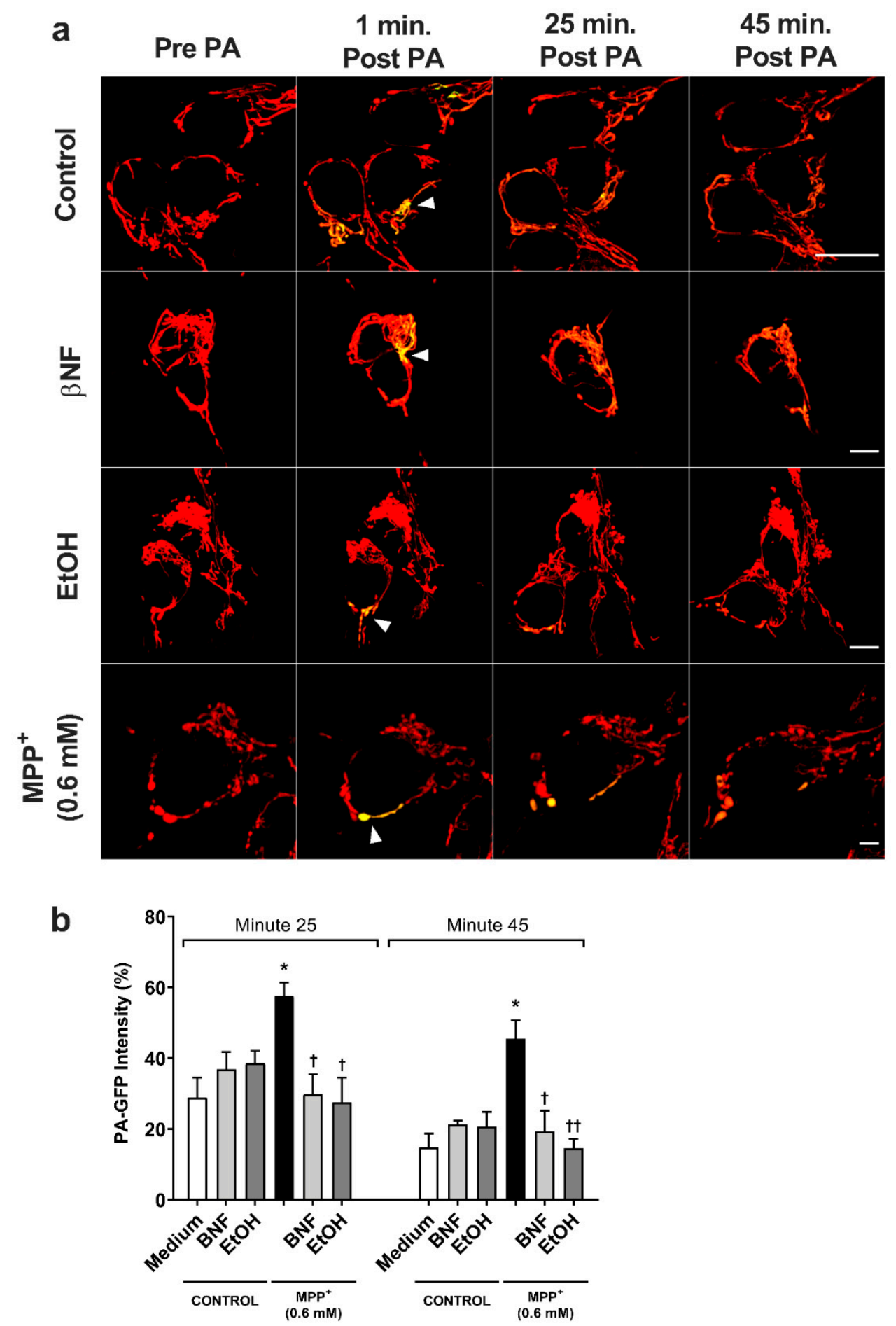

Figure 4. $\mathrm{MPP}^{+}$-induced damage to mitochondrial fusion dynamics in SH-SY5Y cells was reversed by $\beta N F$ and EtOH. (a) Representative confocal images of SH-SY5Y showing the PA-GFP fluorescent spread over the time. Pictures are a combination of red channel for the mitochondrial reporter and the green channel for PA-GFP. Arrowheads point the photo-activated area. Scale bar: $10 \mu \mathrm{m}$. (b) PA-GFP percentage intensity in the photo-activated area at minutes 25 and 45 post-photoactivation. Mitochondrial fusion dynamics after treatment with $\beta \mathrm{NF}+\mathrm{MPP}^{+}(0.6 \mathrm{mM})$ or EtOH $+\mathrm{MPP}^{+}(0.6 \mathrm{mM})$ returned to control values. Intensity in the green channel before photo-activation was taken as $0 \%$, while intensity in one-minute post photo-activation was considered as $100 \%$ intensity. Columns represent mean \pm SEM of independent cell culture preparations $(n \geq 3) .{ }^{*} p<0.05$ vs. medium; ${ }^{{ }^{+\dagger}} p<0.01$, ${ }^{+} p<0.05$ vs. $\mathrm{MPP}^{+} 0.6 \mathrm{mM}$, two-way ANOVA followed by Tukey post-test. 


\subsection{Disruption of $\psi_{m}$ by $M P P^{+}$Is Avoided with CYP-Inducers Treatments}

Because the restoration of mitochondrial kinetics is an indicator of proper mitochondrial functioning, we then assessed whether the treatments with inducers would also be able to restore the $\psi_{\mathrm{m}}$. The red/green fluorescent intensity ratio observed when cells were treated with $\mathrm{MPP}^{+}(1.5 \mathrm{mM})$ was $32.5 \%$ smaller than control samples, indicating a higher accumulation of $5,5^{\prime}, 6,6^{\prime}$-tetrachloro-1,1',3,3' -tetraethyl-benzimidazolocarbocyanine iodide (JC-1) monomers (Figure 5). Both $\beta \mathrm{NF}+\mathrm{MPP}^{+}(1.5 \mathrm{mM})$ and $\mathrm{EtOH}+\mathrm{MPP}^{+}(1.5 \mathrm{mM})$ treatments were able to partially reverse this decrease and showed a significant recover (89\% and 90\%, respectively) in the red/green ratio. An important decrease in JC-1 aggregates in valynomicine control samples confirmed that the observed changes were due to dissipation of the electrochemical potential. These data suggest that the possible protection exerted by the treatments affects mechanisms that are upstream to any impairment of mitochondrial functioning promoted by $\mathrm{MPP}^{+}$toxicity.

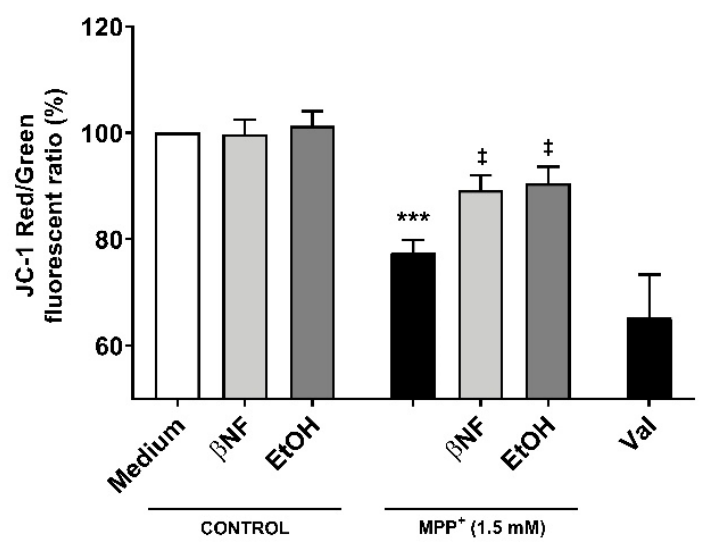

Figure 5. Changes in $\psi_{\mathrm{m}}$ by $\mathrm{MPP}^{+}$were restored by $\beta \mathrm{NF}$ and EtOH treatments. SH-SY5Y cells were treated with $\mathrm{MPP}^{+}(1.5 \mathrm{mM})$ and JC-1 was used to study the $\psi_{\mathrm{m}}$. In control conditions, JC-1 accumulated inside the mitochondria, emitting red fluorescence. When the $\Psi_{\mathrm{m}}$ was disrupted, JC-1 accumulated in cytoplasm, emitting green fluorescence. Valinomycin (Val), which permeabilizes the mitochondrial membrane to potassium, dissipated the mitochondrial electrochemical potential and was used as a positive control to prevent JC-1 aggregation. Data represent the red/green ratio of treated cells and are depicted as a percentage of control samples of independent cell culture preparations $(n \geq 3) .{ }^{* * *} p<0.001$ vs. $\beta N F$ or EtOH; ${ }^{\ddagger} p<0.05$ vs. $\mathrm{MPP}^{+} 1.5 \mathrm{mM}$, two-way ANOVA followed by Tukey post-test.

\subsection{Treatments with $\beta N F$ and EtOH Avoid Decrease of Mitochondrial Complex I Activity by MPP}

In order to assess whether CYP inducers protect the correct functioning of mitochondria from $\mathrm{MPP}^{+}$, a complex I activity assay was carried out. Cells were pre-incubated for 48 hours with $\beta N F$ or EtOH at reported concentrations, then treated with $\mathrm{MPP}^{+}(1.5 \mathrm{mM})$ at the moment of data acquisition. We observed a decrease in the complex I activity of $56 \%$ compared to control (Figure 6 ). The inhibition of complex I activity obtained by rotenone confirmed that complex I was involved in the NADH reduction measured in this assay. Both pre-treatments with $\beta \mathrm{NF}$ and EtOH significantly reduced the toxic effect of $\mathrm{MPP}^{+}$, showing only 33\% and 11\% decreases of complex I activity, respectively. These data suggest that CYP induction predisposes the cells to be more efficient in avoiding the toxicity produced by $\mathrm{MPP}^{+}$, and that this protection occurs before the toxin disrupts the mitochondrial complex I activity. Overall, the presented data suggest that $\beta \mathrm{NF}$ and EtOH, possibly by inducing CYPs, protect the SH-SY5Y cells against toxic insult by $\mathrm{MPP}^{+}$. 


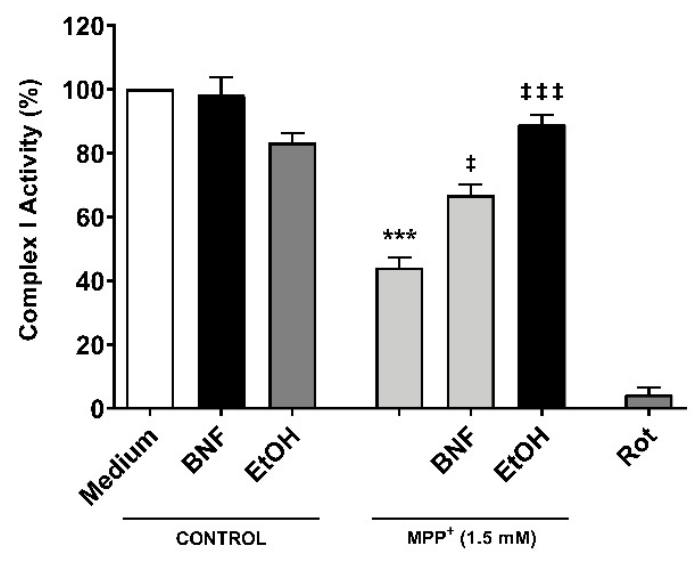

Figure 6. Reduction of mitochondrial complex I activity by $\mathrm{MPP}^{+}$was partially avoided with $\beta \mathrm{NF}$ and EtOH pre-treatments. SH-SY5Y cells were pre-incubated with either inducer for 48 hours prior exposure to $\mathrm{MPP}^{+}$in the moment of data acquisition. Rotenone (Rot) was used as control for NADH reduction by complex I. Columns represent the percentage of complex I activity of each group (see Methods) and represent the mean $\pm \mathrm{SEM}$ of independent cell culture preparations $(n=3)$. ${ }^{* * *} p<0.001 \mathrm{vs}$. $\beta \mathrm{NF}$ or EtOH; ${ }^{\ddagger \ddagger \ddagger} p<0.001,{ }^{\ddagger} p<0.05$, vs. $\mathrm{MPP}^{+} 1.5 \mathrm{mM}$, two-way ANOVA followed by Tukey post-test.

\section{Discussion}

Exposure to xenobiotics is one of the major causes of oxidative stress and apoptosis in the CNS and increases the risk of developing neurodegenerative diseases such as PD [22]. A mechanism by which the cells eliminate xenobiotics is the CYP system, which is involved in the metabolism of most of the drugs and toxins that cross the blood-brain barrier. Among the several isoforms that can be found in this super-family, most of them can be upregulated by at least a few xenobiotics [11]. In our previous publication, we demonstrated that $\beta \mathrm{NF}$ and $\mathrm{EtOH}$ are able to induce the expression of two isoforms in SH-SY5Y cells, CYP 2D6 and 2E1 [20]. However, the mechanisms by which CYP isoforms can influence the overall homeostasis of the brain are poorly understood. In this study, we used SH-SY5Y cells to induce the expression of CYPs prior to exposure to $\mathrm{MPP}^{+}$, with the aim to study how these two isoforms protect mitochondria against $\mathrm{MPP}^{+}$toxicity. Other publication has also shown that the apoptosis caused by MPP ${ }^{+}$is mediated by ROS production [23]. We showed that both $\beta N F$ and $\mathrm{EtOH}$ treatments rescue the decrease in cell viability promoted by $\mathrm{MPP}^{+}$. Additionally, we presented evidence that the observed neuroprotection is linked to a reduction of ROS formation, restoration of $\psi_{\mathrm{m}}$, and mitochondrial fusion kinetics. Finally, we showed that the toxic effect is avoided before $\mathrm{MPP}^{+}$affects the mitochondrial complex I activity. Taken together, these results suggest that induction of CYPs by $\beta N F$ and EtOH may contribute to neuroprotection of SH-SY5Y against $\mathrm{MPP}^{+}$toxicity; however, other molecular mechanisms involving neuroprotection pathways not related with CYPs may not be discarded.

The difference in cell viability responses with both concentrations of $\mathrm{MPP}^{+}$outline a possible role of CYPs in $\mathrm{MPP}^{+}$clearance. Indeed, the active site of CYP 2D6 is large enough to allow the entry of $\mathrm{MPP}^{+}$into it, while the active site of 2E1 is smaller, as reported by Gay and colleagues [24]. In this line, a higher presence of CYPs delays the toxicity promoted by $\mathrm{MPP}^{+}$, thus observing only late apoptotic or necrotic cells with high concentrations of this toxin. Moreover, our results in mitochondrial functionality are in agreement with those of cell viability. Despite the molecular mechanisms by which CYP 2D6 or 2E1 avoid the toxic effects of $\mathrm{MPP}^{+}$remain unclear, our data are congruent among them and link the rescue in cell viability with restoration of mitochondrial functionality. It is well established that $\mathrm{MPP}^{+}$exerts its toxic effects through inhibition of complex I, disrupting the ATP production and increasing ROS release [25]. According to this mechanistic action, the restoration of mitochondrial homeostasis may be directly related to a decrease in ROS production and a correct functioning of the respiratory chain complex I, as shown in our results. 
Consistent with our hypothesis, Mann and colleagues demonstrated that inhibition of CYP 2D6 with quinidine $(0.1 \mu \mathrm{M})$ increased toxicity and cell death of $\mathrm{MPP}^{+}$in SH-SY5Y cells [26]. Similar results implicating the protective role of this isoform, although in undifferentiated and differentiated PC12 cells, were also reported by Matoh and colleagues, who showed that cells overexpressing CYP $2 D 6$ cDNA reduced the toxicity and the ROS production promoted by $\mathrm{MPP}^{+}$[27]. Although the neuroprotective role that CYP 2D6 plays in the CNS is still under debate, it may present a dual role in terms of xenobiotic clearance. Indeed, CYP 2D6 have also been involved in the activation of MPTP to $\mathrm{MPP}^{+}$, increasing ROS production, altering mitochondrial morphology, and decreasing complex I activity in cultures of Neuro-2A cells expressing CYP 2D6 in mitochondria [28]. More studies are necessary to relate the metabolic activity of CYP 2D6 to $\mathrm{MPP}^{+}$detoxification. It has been shown by our group as well as others that, in neurons, the CYP 2D6 isoform localizes in mitochondria, supporting a possible interaction between both molecules [20,29-31].

Our findings are also consistent with other published studies in which the protective role of CYP 2E1 against $\mathrm{MPP}^{+}$toxicity is observed. The role for this isoenzyme in dopaminergic cells is still under study. However, it has been related with $\mathrm{MPP}^{+}$accumulation in vitro rather than with metabolic activity [32]. In mesencephalic cell cultures from CYP 2E1-null mice, the lack of this isoform contributed to the intracellular accumulation of $\mathrm{MPP}^{+}$[33]. The same result was observed in CYP 2E1 knock-out mesencephalic cultures, where the $\mathrm{MPP}^{+}$accumulation was double that in wild-type cells [34]. However, Hao and colleagues showed opposite results in astrocytes, in which the inhibition of CYP 2E1 activity with diallylsulphide avoided the loss of cell viability by $\mathrm{MPP}^{+}$and decreased the ROS production [35].

\section{Materials and Methods}

\subsection{Products}

$\beta \mathrm{NF}$ (Cat\# N3633), EtOH (Cat\# E7023), 3-(4,5-dimethylthiazol-2-yl)-2,5-diphenyltetrazolium bromide (MTT; Cat\# M2128), 1-methyl-4-phenylpyridinium iodide (MPP ${ }^{+}$; Cat\# D048), mitochondria staining kit containing 5, $5^{\prime}, 6,6^{\prime}$-tetrachloro-1,1',3,3'-tetraethyl-benzimidazolocarbocyanine iodide (JC-1; Cat\# CS0390), 2' $7^{\prime}$-dichlorofluorescin diacetate (DCFH-DA; Cat\# 287810), dimethyl sulfoxide (DMSO; Cat\# D8418), and the materials used for cell culture were obtained from Sigma-Aldrich (Milan, Italy). The mitochondrial complex I activity kit (Cat\# BVN-K520) was obtained from Vinci-Biochem (Florence, Italy). The Alexa fluor 488 ${ }^{\mathrm{TM}}$-Annexin V/ propidium iodide (PI) double staining kit (Cat\# V13245), the opti-MEM media (Cat\# 11058021), and the Lipofectamine ${ }^{\circledR} 2000$ reagent (Cat\# 11668019) were purchased from Life Technologies (Monza, Italy). The mitochondrial reporter (Ds-Red vector) and the plasmid containing the photo-activatable green fluorescent protein (PA-GFP) gene were kindly provided by Professor Richard Youle, NIH (Bethesda, MD, USA).

\subsection{Cell Culture and Treatments with CYP Inducers and/or MPP}

Human neuroblastoma SH-SY5Y cells (ECACC Cat\# 94030304) were obtained from Sigma-Aldrich (Milan, Italy) and cultured into polystyrene-coated flasks in RPMI medium (Cat\# R8758) supplemented with 10\% fetal bovine serum (Cat\# F2442), $100 \mathrm{U} / \mathrm{mL}$ of penicillin, and $100 \mu \mathrm{g} / \mathrm{mL}$ streptomycin (Cat\# P4333). Cells were incubated at $37^{\circ} \mathrm{C}$ in $5 \% \mathrm{CO}_{2}$ and medium was changed two times a week. Once a week, when flasks were at about $80 \%$ confluency, the culture was passaged at a ratio of 1:10. Only cultures between passages 3-18 were used.

Cells were seeded in 96-well plates at a concentration of $1.6 \times 10^{4}$ cells/well for MTT assay, mitochondrial complex I activity, and JC-1 experiments, or in 24 -well plates at $4.0 \times 10^{4}$ cells/well for ROS detection. In Annexin V/PI and cell cycle experiments, the cells were seeded in 6-well plates at a concentration of $4 \times 10^{5}$ cells/well. After $24 \mathrm{~h}$, the cells were treated as summarized in Table 1, except for mitochondrial complex I activity experiments (see corresponding section for treatment details). In brief, the medium was replaced with fresh medium containing $\beta \mathrm{NF}(4 \mu \mathrm{M})$ or $\mathrm{EtOH}(100 \mathrm{mM})$, and 
cells were incubated for another $24 \mathrm{~h}$. The medium was then replaced with fresh medium containing the same inducer plus $\mathrm{MPP}^{+}(0.6$ or $1.5 \mathrm{mM})$ and left for additional 24 hours. Afterwards, cells were used for data acquisition as detailed below. The study was not pre-registered, and no blinding or sample size calculation was performed.

\subsection{MTT Assay}

The transformation of MTT to formazan due to normal metabolic activity, a measure of cell viability, was determined as previously reported [20]. In brief, the culture medium was aspirated, and cells were treated with an MTT solution of $0.5 \mathrm{mg} / \mathrm{mL}$ in fresh medium and incubated for $90 \mathrm{~min}$ at $37^{\circ} \mathrm{C}$ and $5 \% \mathrm{CO}_{2}$. The solution was then aspirated, and the resulting formazan was dissolved in DMSO. After shaking the plate for $10 \mathrm{~min}$, absorbance was measured by Multiskan GO (Cat\# 10588; Thermo Scientific, Milan, Italy) plate reader with SkanIt software version 3.2 (Thermo Scientific, Milan, Italy) at a wavelength of $540 \mathrm{~nm}$. Mean values of absorbance of each treatment from independent experiments were normalized to mean control absorbance values, taken as $100 \%$ viability.

\subsection{Apoptosis Assays}

Exposed phosphatidylserine was detected by flow cytometry using the Alexa fluor $488^{\mathrm{TM}}$-Annexin V/PI double staining kit. The staining protocol used for this assay was followed according to manufacturer indications and as previously published [36] with some modifications. In brief, after the treatments described above, the cells were resuspended in $1 \mathrm{X}$ annexin-binding buffer and stained with Alexa fluor $488^{\mathrm{TM}}$-Annexin V and PI $(100 \mu \mathrm{g} / \mathrm{mL})$ for $15 \mathrm{~min}$ at room temperature. The samples were then read with a BD FACSCalibur Flow Cytometry System (BD Biosciences, San Jose, CA, USA) with CELLQuest Pro software version 3.3 (BD Biosciences, San Jose, CA, USA). Excitation of both fluorescent markers was carried out with a laser at $488 \mathrm{~nm}$, and annexin $\mathrm{V}$ and PI were read by using channels FL1 and FL2, respectively. A minimum of $10^{4}$ cells were collected, and then samples were analyzed with FlowJo ${ }^{\mathrm{TM}}$ software vX.0.7 (Becton, Dickinson and Company, Ashland, OR, USA). During the first stages of apoptosis, phosphatidylserine was translocated to the extracellular surface of the membrane and was recognized by annexin V. PI is impermeable to the plasma membrane and only could enter the cells when this was broken during the last stages of apoptosis. Therefore, the population that resulted as a double negative was considered to be healthy. Annexin V positive and PI negative was considered as early apoptotic, double positive was considered as late apoptotic, and annexin V negative and PI positive was considered as a necrotic population.

Cell cycle analysis was also performed to check for apoptotic cells by flow cytometry as previously described by Santulli and colleagues [37]. Briefly, after the treatments detailed before, the cells were fixed with $70 \%$ of ice-cold ethanol, treated with RNase $(10 \mathrm{mg} / \mathrm{mL})$, stained with PI $(2 \mathrm{mg} / \mathrm{mL})$, and incubated for $30 \mathrm{~min}$ at room temperature in darkness. Red fluorescence (DNA) was detected through a 563-607 nm band-pass filter using a BD FACSCalibur Flow Cytometry System. A minimum of $10^{4}$ cells per sample were collected, and the percentage of apoptotic cell accumulated in the sub-G0/G1 peak was calculated by using Cell Quest Pro software version 3.3.

\subsection{Mitochondrial Fusion Dynamics}

The cells were seeded in a glass bottom dish $(20 \mathrm{~mm})$ at a concentration of $4 \times 10^{5}$ cells/dish. A day after, cells were transfected with ds-Red (to colocalize mitochondrial) and PA-GFP plasmids (to report fusion dynamics) at a 1:1 proportion (plasmid/plasmid) in opti-MEM medium with lipofectamine transfection reagent at $1: 2$ ratio (plasmid/lipofectamine). Cells were incubated overnight at $37^{\circ} \mathrm{C}$ and $5 \% \mathrm{CO}_{2}$ and treated with inducers and $\mathrm{MPP}^{+}(0.6 \mathrm{mM})$ as detailed in Table 1. Data were acquired as described by Lovy and colleagues [38] with some modifications. In brief, a small region of interest $\left(\sim 10 \mu \mathrm{m}^{2}\right)$ of the cell was photo-activated at $405 \mathrm{~nm}$ with a $40 \%$ UV laser. One-minute post photo-activation, cells were photographed every $5 \mathrm{~min}$ for $55 \mathrm{~min}$. PA-GFP intensity in pre-photo-activated pictures was taken as $0 \%$ intensity, while one-minute post photo-activation was 
considered as $100 \%$ intensity. In healthy cells, intensity decreased over the time in the photo-activated area, indicating high fusion dynamics, while impaired mitochondria retained the fluorescent signal due to a lower fusion rate. Data were acquired with a super-solution Leica motorized inverted microscope (Leica SP8 Gated STED, Leica Microsystems, Ashbourne, Ireland), and analysis was performed with Leica Application Suite X software, version 3.7 (Leica Microsystems, Ashbourne, Ireland).

\subsection{Mitochondrial Complex I Activity}

The Complex I activity experiments were carried out following manufacturer indications and as described by Brown and Brand [39] with some modifications. In brief, cells were treated with $\beta \mathrm{NF}$ $(4 \mu \mathrm{M})$ or EtOH $(100 \mathrm{mM})$ for 48 hours to promote induction of CYPs. After incubation, the medium was replaced for assay buffer containing KCN (100 mM), fatty acid free-BSA (1:20), and bovine heart mitochondria (1:50). Then, test compound $\left(\mathrm{MPP}^{+} 1.5 \mathrm{mM}\right.$ ), positive control (rotenone, $1 \mu \mathrm{M}$ ) or vehicle, diluted in assay buffer, were added to each well. Finally, buffer containing NADH reagent (1:23) and ubiquinone reagent (1:34) was added to each well. Immediately after, data were acquired in a plate reader by measuring the absorbance at $340 \mathrm{~nm}$ every $30 \mathrm{~s}$ during $15 \mathrm{~min}$ at room temperature. Absorbance was plotted versus time, and slope was calculated. The complex I activity (\%) was determined by dividing the slope of each sample by the control slope value.

\subsection{Mitochondrial Electrochemical Potential Gradient}

Changes in the $\psi_{\mathrm{m}}$ were detected with a carbocyanine dye JC-1 kit following manufacturer's indications. Under normal $\psi_{\mathrm{m}}$, JC-1 accumulated inside mitochondria, forming aggregates that emitted a red fluorescence; under depolarized $\psi_{\mathrm{m}}, \mathrm{JC}-1$ diffused to the cytoplasm and formed monomers that emitted a green fluorescence. After treating the cells as described in Table 1, a Fluoroskan Ascent fluorimeter (Cat\# 1506450; Thermo Labsystems, Milan, Italy) was used to measure the red(aggregated JC-1, intact mitochondria, $525 \mathrm{~nm}$ excitation, $590 \mathrm{~nm}$ emission) or the green-fluorescence (monomeric JC-1, disrupted mitochondria, $490 \mathrm{~nm}$ excitation, $530 \mathrm{~nm}$ emission). Mitochondrial membrane depolarization was indicated by a decrease in the red/green fluorescence intensity ratio. Valinomycin $(0.2 \mathrm{ng} / \mu \mathrm{L}$ for $20 \mathrm{~min})$ was used as a positive control.

\subsection{ROS Detection}

ROS generation was assessed as previously described by Brizi and colleagues [40] with some modifications. In brief, after treatments described in Table 1, cells were rinsed with phosphate buffered saline (PBS) and loaded with $10 \mu \mathrm{M} \mathrm{2} 2^{\prime}, 7^{\prime}$-dichlorofluorescin diacetate (DCFDA) for $15 \mathrm{~min}$ at $37^{\circ} \mathrm{C}$, then washed, centrifuged at $13,000 \times g$ for $5 \mathrm{~min}$, and re-suspended in $0.7 \mathrm{~mL}$ of phosphate buffered saline (Cat\# P5493; Sigma-Aldrich, Milan, Italy). The intracellular fluorescence (504 nm excitation, $529 \mathrm{~nm}$ emission) was acquired with a Fluoroskan Ascent fluorimeter, and data were normalized to $\mathrm{mg}$ of cellular protein of the samples and expressed as percent of untreated control cells.

\subsection{Statistical Analysis}

Data were reported as mean \pm SEM and analyzed for statistical significance by two-way ANOVA followed by Tukey's multiple comparison test with IBM SPSS Statistics for windows, version 26 (IBM Corp., Armonk, N.Y., USA). No exclusion criteria were pre-determined. No normality test to analyze the data distribution was performed. Outliers that were two standards deviation away from the mean were excluded from the analysis, since they likely represent technical errors.

\section{Conclusions}

We propose that the neuroprotection mediated by $\beta \mathrm{NF}$ and EtOH may be carried out by the metabolic activity of CYP 2D6 in mitochondria and by the role of CYP 2E1 in the efflux and the accumulation of $\mathrm{MPP}^{+}$. However, other pathways promoted by $\beta \mathrm{NF}, \mathrm{EtOH}$, and independent from 
CYP induction should not be discarded. Taken together, these results support a possible role of CYP 2D6 and 2E1 as a potential neuroprotective system against xenobiotic insult in undifferentiated SH-SY5Y cells. Further research is needed to establish this CYP induction model in other cell lines and primary cultures and to confirm a direct implication of CYP in $\mathrm{MPP}^{+}$neuroprotection, thus the impact that these isoforms have in the metabolism of other xenobiotics bring new insights for future therapeutic approaches.

Supplementary Materials: Supplementary materials can be found at http://www.mdpi.com/1422-0067/21/11/ 3955/s1.

Author Contributions: Conceptualization, J.F.A., M.F., G.P.D. and M.V.; methodology, J.F.A. and M.V.; validation, J.F.A., M.F. and M.V.; formal analysis, J.F.A. and M.F.; investigation, J.F.A. and E.C.; resources, M.F., G.P.D. and M.V.; data curation, J.F.-A.; writing—original draft preparation, J.F.-A.; writing - review and editing, J.F.-A., M.F., G.P.D. and M.V.; visualization, J.F.-A.; supervision, M.F., G.P.D. and M.V.; project administration, G.P.D. and M.V.; funding acquisition, J.F.-A., G.P.D. and M.V. All authors have read and agreed to the published version of the manuscript.

Funding: Jesus Fernandez-Abascal has been funded by Marie Sklodowska-Curie Actions of the European Union's Seventh Framework Programme FP7 under REA grant agreement for “Training in Neurodegeneration, Therapeutics Intervention, and Neurorepair" project, $\mathrm{n}^{\circ} 608381$.

Acknowledgments: We thank Richard Youle, NIH (USA) for sharing the Ds-Red and PA-GFP vectors. We thank Gavin McManus and Gerard Esteban (Trinity Biomedical Science Institute, Trinity College Dublin, Ireland) for their assistance in confocal microscopy experiments. We thank Nicole Encalada for proof-reading the manuscript.

Conflicts of Interest: The authors declare no conflict of interest.

$\begin{array}{ll}\text { Abbreviations } \\ \text { CNS } & \text { Central Nervous System } \\ \text { CYP } & \text { Cytochrome P450 } \\ \text { DCFH } & 2^{\prime}, 7^{\prime} \text {-dichlorofluorescein } \\ \text { DCFH-DA } & 2^{\prime}, 7^{\prime} \text {-dichlorofluorescin diacetate } \\ \text { EtOH } & \text { Ethanol } \\ \text { JC-1 } & 5,5^{\prime}, 6,6^{\prime} \text {-tetrachloro-1, } 1^{\prime}, 3,3^{\prime} \text {-tetraethyl-benzimidazolocarbocyanine iodide } \\ \text { MPP } & \text { 1-methyl-4-phenylpyridinium } \\ \text { MTT } & \text { 3-(4,5-dimethylthiazol-2-yl)-2,5-diphenyltetrazolium bromide } \\ \text { PA-GFP } & \text { Photo-activatable green fluorescent protein } \\ \text { PD } & \text { Parkinson's disease } \\ \text { PI } & \text { Propidium Iodide } \\ \text { ROS } & \text { Reactive oxygen species } \\ \beta N F & \beta \text {-naphthoflavone } \\ \psi_{m} & \text { Mitochondrial membrane potential }\end{array}$

\section{References}

1. Shulman, J.M.; De Jager, P.L.; Feany, M.B. Parkinson's disease: Genetics and pathogenesis. Annu. Rev. Pathol. 2011, 6, 193-222. [CrossRef] [PubMed]

2. He, Z.X.; Chen, X.W.; Zhou, Z.W.; Zhou, S.F. Impact of physiological, pathological and environmental factors on the expression and activity of human cytochrome P450 2D6 and implications in precision medicine. Drug Metab. Rev. 2015, 47, 470-519. [CrossRef] [PubMed]

3. Lu, Y.; Peng, Q.; Zeng, Z.; Wang, J.; Deng, Y.; Xie, L.; Mo, C.; Zeng, J.; Qin, X.; Li, S. CYP2D6 phenotypes and Parkinson's disease risk: A meta-analysis. J. Neurol. Sci. 2014, 336, 161-168. [CrossRef] [PubMed]

4. Ma, C.; Liu, Y.; Neumann, S.; Gao, X. Nicotine from cigarette smoking and diet and Parkinson disease: A review. Transl. Neurodegener. 2017, 6, 18. [CrossRef] [PubMed]

5. Palacios, N. Air pollution and Parkinson's disease-Evidence and future directions. Rev. Environ. Health 2017. [CrossRef]

6. Subramaniam, S.R.; Chesselet, M.F. Mitochondrial dysfunction and oxidative stress in Parkinson's disease. Prog. Neurobiol. 2013, 106, 17-32. [CrossRef] 
7. Franco-Iborra, S.; Vila, M.; Perier, C. Mitochondrial Quality Control in Neurodegenerative Diseases: Focus on Parkinson's Disease and Huntington's Disease. Front. Neurosci. 2018, 12, 342. [CrossRef]

8. Gulbins, E.; Dreschers, S.; Bock, J. Role of mitochondria in apoptosis. Exp. Physiol. 2003, 88, 85-90. [CrossRef]

9. Lin, M.T.; Beal, M.F. Mitochondrial dysfunction and oxidative stress in neurodegenerative diseases. Nature 2006, 443, 787-795. [CrossRef]

10. Toselli, F.; Dodd, P.R.; Gillam, E.M. Emerging roles for brain drug-metabolizing cytochrome P450 enzymes in neuropsychiatric conditions and responses to drugs. Drug Metab. Rev. 2016, 48, 379-404. [CrossRef]

11. McMillan, D.M.; Tyndale, R.F. CYP-mediated drug metabolism in the brain impacts drug response. Pharmacol. Ther. 2018. [CrossRef] [PubMed]

12. Ferguson, C.S.; Tyndale, R.F. Cytochrome P450 enzymes in the brain: Emerging evidence of biological significance. Trends Pharmacol. Sci. 2011, 32, 708-714. [CrossRef] [PubMed]

13. Meyer, R.P.; Gehlhaus, M.; Knoth, R.; Volk, B. Expression and function of cytochrome p450 in brain drug metabolism. Curr. Drug Metab. 2007, 8, 297-306. [CrossRef] [PubMed]

14. Ur Rasheed, M.S.; Mishra, A.K.; Singh, M.P. Cytochrome P450 2D6 and Parkinson's Disease: Polymorphism, Metabolic Role, Risk and Protection. Neurochem. Res. 2017. [CrossRef]

15. Miksys, S.; Tyndale, R.F. Nicotine induces brain CYP enzymes: Relevance to Parkinson's disease. J. Neural. Transm. Suppl. 2006, 70, 177-180.

16. Valencia-Olvera, A.C.; Moran, J.; Camacho-Carranza, R.; Prospero-Garcia, O.; Espinosa-Aguirre, J.J. CYP2E1 induction leads to oxidative stress and cytotoxicity in glutathione-depleted cerebellar granule neurons. Toxicol. In Vitro 2014, 28, 1206-1214. [CrossRef]

17. Hellum, B.H.; Nilsen, O.G. The in vitro inhibitory potential of trade herbal products on human CYP2D6-mediated metabolism and the influence of ethanol. Basic Clin. Pharmacol. Toxicol. 2007, 101, 350-358. [CrossRef]

18. Miller, R.T.; Miksys, S.; Hoffmann, E.; Tyndale, R.F. Ethanol self-administration and nicotine treatment increase brain levels of CYP2D in African green monkeys. Br. J. Pharmacol. 2014, 171, 3077-3088. [CrossRef]

19. Pretti, C.; Salvetti, A.; Longo, V.; Giorgi, M.; Gervasi, P.G. Effects of beta-naphthoflavone on the cytochrome P450 system, and phase II enzymes in gilthead seabream (Sparus aurata). Comp. Biochem. Physiol. C Toxicol. Pharmacol. 2001, 130, 133-144. [CrossRef]

20. Fernandez-Abascal, J.; Ripullone, M.; Valeri, A.; Leone, C.; Valoti, M. Beta-Naphtoflavone and Ethanol Induce Cytochrome P450 and Protect towards MPP(+) Toxicity in Human Neuroblastoma SH-SY5Y Cells. Int. J. Mol. Sci. 2018, 19, 3369. [CrossRef]

21. Sylvester, P.W. Optimization of the tetrazolium dye (MTT) colorimetric assay for cellular growth and viability. Methods Mol. Biol. 2011, 716, 157-168. [PubMed]

22. Ramsay, R.R.; Majekova, M.; Medina, M.; Valoti, M. Key Targets for Multi-Target Ligands Designed to Combat Neurodegeneration. Front. Neurosci. 2016, 10, 375. [CrossRef] [PubMed]

23. Pizarro, J.G.; Junyent, F.; Verdaguer, E.; Jordan, J.; Beas-Zarate, C.; Pallas, M.; Camins, A.; Folch, J. Effects of $\mathrm{MPP}+$ on the molecular pathways involved in cell cycle control in B65 neuroblastoma cells. Pharmacol. Res. 2010, 61, 391-399. [CrossRef] [PubMed]

24. Gay, S.C.; Roberts, A.G.; Halpert, J.R. Structural features of cytochromes P450 and ligands that affect drug metabolism as revealed by X-ray crystallography and NMR. Future Med. Chem. 2010, 2, 1451-1468. [CrossRef]

25. Kalivendi, S.V.; Kotamraju, S.; Cunningham, S.; Shang, T.; Hillard, C.J.; Kalyanaraman, B. 1-Methyl-4-phenylpyridinium (MPP+)-induced apoptosis and mitochondrial oxidant generation: Role of transferrin-receptor-dependent iron and hydrogen peroxide. Biochem. J. 2003, 371, 151-164. [CrossRef]

26. Mann, A.; Tyndale, R.F. Cytochrome P450 2D6 enzyme neuroprotects against 1-methyl-4-phenylpyridinium toxicity in SH-SY5Y neuronal cells. Eur. J. Neurosci. 2010, 31, 1185-1193. [CrossRef]

27. Matoh, N.; Tanaka, S.; Takehashi, M.; Banasik, M.; Stedeford, T.; Masliah, E.; Suzuki, S.; Nishimura, Y.; Ueda, K. Overexpression of CYP2D6 attenuates the toxicity of MPP+ in actively dividing and differentiated PC12 cells. Gene Expr. 2003, 11, 117-124. [CrossRef]

28. Bajpai, P.; Sangar, M.C.; Singh, S.; Tang, W.; Bansal, S.; Chowdhury, G.; Cheng, Q.; Fang, J.K.; Martin, M.V.; Guengerich, F.P.; et al. Metabolism of 1-methyl-4-phenyl-1,2,3,6-tetrahydropyridine by mitochondrion-targeted cytochrome P450 2D6: Implications in Parkinson disease. J. Biol. Chem. 2013, 288, 4436-4451. [CrossRef] 
29. Avadhani, N.G.; Sangar, M.C.; Bansal, S.; Bajpai, P. Bimodal targeting of cytochrome P450s to endoplasmic reticulum and mitochondria: The concept of chimeric signals. FEBS J. 2011, 278, 4218-4229. [CrossRef]

30. Marini, S.; Nannelli, A.; Sodini, D.; Dragoni, S.; Valoti, M.; Longo, V.; Gervasi, P.G. Expression, microsomal and mitochondrial activities of cytochrome P450 enzymes in brain regions from control and phenobarbital-treated rabbits. Life Sci. 2007, 80, 910-917. [CrossRef]

31. Miksys, S.; Rao, Y.; Sellers, E.M.; Kwan, M.; Mendis, D.; Tyndale, R.F. Regional and cellular distribution of CYP2D subfamily members in rat brain. Xenobiotica 2000, 30, 547-564. [CrossRef] [PubMed]

32. Garcia-Suastegui, W.A.; Ramos-Chavez, L.A.; Rubio-Osornio, M.; Calvillo-Velasco, M.; Atzin-Mendez, J.A.; Guevara, J.; Silva-Adaya, D. The Role of CYP2E1 in the Drug Metabolism or Bioactivation in the Brain. Oxid. Med. Cell. Longev. 2017, 2017, 4680732. [CrossRef] [PubMed]

33. Pardini, C.; Vaglini, F.; Viaggi, C.; Caramelli, A.; Corsini, G.U. Role of CYP2E1 in the mouse model of MPTP toxicity. Parkinsonism Relat. Disord. 2008, 14, S119-S123. [CrossRef] [PubMed]

34. Vaglini, F.; Viaggi, C.; Piro, V.; Pardini, C.; Gerace, C.; Scarselli, M.; Corsini, G.U. Acetaldehyde and parkinsonism: Role of CYP450 2E1. Front. Behav. Neurosci. 2013, 7, 71. [CrossRef] [PubMed]

35. Hao, C.; Liu, W.; Luan, X.; Li, Y.; Gui, H.; Peng, Y.; Shen, J.; Hu, G.; Yang, J. Aquaporin-4 knockout enhances astrocyte toxicity induced by 1-methyl-4-phenylpyridinium ion and lipopolysaccharide via increasing the expression of cytochrome P4502E1. Toxicol. Lett. 2010, 198, 225-231. [CrossRef] [PubMed]

36. Durante, M.; Frosini, M.; Fusi, F.; Neri, A.; Sticozzi, C.; Saponara, S. In vitro vascular toxicity of tariquidar, a potential tool for in vivo PET studies. Toxicol. In Vitro 2017, 44, 241-247. [CrossRef]

37. Santulli, C.; Brizi, C.; Micucci, M.; Del Genio, A.; De Cristofaro, A.; Bracco, F.; Pepe, G.L.; Di Perna, I.; Budriesi, R.; Chiarini, A.; et al. Castanea sativa Mill. Bark Extract Protects U-373 MG Cells and Rat Brain Slices Against Ischemia and Reperfusion Injury. J. Cell. Biochem. 2017, 118, 839-850. [CrossRef]

38. Lovy, A.; Molina, A.J.; Cerqueira, F.M.; Trudeau, K.; Shirihai, O.S. A faster, high resolution, mtPA-GFP-based mitochondrial fusion assay acquiring kinetic data of multiple cells in parallel using confocal microscopy. J. Vis. Exp. JoVE 2012. [CrossRef]

39. Brown, G.C.; Brand, M.D. Proton/electron stoichiometry of mitochondrial complex I estimated from the equilibrium thermodynamic force ratio. Biochem. J. 1988, 252, 473-479. [CrossRef]

40. Brizi, C.; Santulli, C.; Micucci, M.; Budriesi, R.; Chiarini, A.; Aldinucci, C.; Frosini, M. Neuroprotective Effects of Castanea sativa Mill. Bark Extract in Human Neuroblastoma Cells Subjected to Oxidative Stress. J. Cell. Biochem. 2016, 117, 510-520. [CrossRef] 